\title{
Do myoepithelial cells hold the key for breast tumor progression?
}

\author{
Kornelia Polyak ${ }^{1,2,3}$ and Min $\mathrm{Hu}^{1,2}$ \\ ${ }^{1}$ Department of Medical Oncology, Dana Farber Cancer Institute, 44 Binney Street \\ and ${ }^{2}$ Harvard Medical School, Boston, MA 02115
}

${ }^{3}$ Correspondence: Kornelia Polyak, Department of Medical Oncology, Dana Farber Cancer Institute, 44 Binney Street D740C, Boston, MA 02115. Phone: (617) 632-2106; Fax: (617) 632-4005; Email: Kornelia_Polyak@dfci.harvard.edu 


\begin{abstract}
Mammary myoepithelial cells have been the foster child of breast cancer biology and have been largely ignored since they were considered to be less important for tumorigenesis than luminal epithelial cells from which most of breast carcinomas are thought to arise. In recent years as our knowledge in stem cell biology and the cellular microenvironment has been increasing myoepithelial cells are slowly starting to gain more attention. Emerging data raise the hypothesis if myoepithelial cells play a key role in breast tumor progression by regulating the in situ to invasive carcinoma transition and if myoepithelial cells are part of the mammary stem cell niche. Paracrine interactions between myoepithelial and luminal epithelial cells are known to be important for cell cycle arrest, establishing epithelial cell polarity, and inhibiting migration and invasion. Based on these functions normal mammary myoepithelial cells have been called "natural tumor suppressors". However, during tumor progression myoepithelial cells seem to loose these properties and eventually they themselves diminish as tumors become invasive. Better understanding of myoepithelial cell function and their role in tumor progression may lead to their exploitation for cancer therapeutic and preventative measures.
\end{abstract}

KEYWORDS: myoepithelium, tumor progression, DCIS (ductal carcinoma in situ), paracrine factor, SAGE (Serial Analysis of Gene Expression) 


\section{INTRODUCTION}

Breast cancer is the most commonly identified and one of the deadliest neoplasms in women in Western countries. The recent trend toward improvement in breast cancer mortality rate is largely due to increased diagnosis of early stage disease, while our therapeutic options for advanced stage breast carcinomas are still fairly limited. Thus, there is a need to better understand the molecular basis of breast tumor progression and to use this knowledge for the design of targeted, molecular based therapies. Recently developed technologies have enabled us to analyze molecular differences between normal and cancer cells at a genome-wide level in comprehensive and unbiased ways, allowing the molecular based classification of breast cancer and identification gene signatures correlating with metastatic behavior and clinical outcome (1-5). However, since most of these studies were using bulk tissue samples that are composed of multiple cell types, the specific contribution of epithelial, myoepithelial, and various stromal cells to these tumor classifiers and prognostic signatures is unknown.

In the past decades the major focus of cancer research has been the transformed tumor cell itself, while the role of the cellular microenvironment in tumorigenesis has not been widely explored. Epithelialmesenchymal interactions are known to be important for the normal development of the mammary gland and to play a role in breast tumorigenesis (6-13). Early studies demonstrated that normal mammary microenvironment is capable of "reverting" the neoplastic phenotype of breast cancer cells by inducing cellular differentiation $(14,15)$, suggesting that cancer cells can thrive only in a distorted environment or have to become independent of extracellular signals. The contribution of genetic host factors to tumor initiation, progression, and angiogenesis also support a role for non-epithelial cells in carcinogenesis (16, 17). This was dramatically illustrated by the results that systemic inactivation of TGF- $\beta$ type II receptor in stromal fibroblasts led to prostate and gastric epithelial neoplasia (18), while its inactivation in mammary stromal fibroblasts led to abnormal ductal development and promoted the growth of transplanted tumors (19). Similarly a recent finding demonstrating that mammary tumors were only formed in cleared mammary fat pads of rats treated with carcinogens, regardless of whether the epithelial cells were treated 
with carcinogens in vitro, also emphasizes the importance of stromal alterations in the initiating steps of breast cancer (20). However, this finding could not be confirmed in mouse mammary glands where DMBA treatment of the stroma had no effect on mammary tumorigenesis (21) suggesting differences among species or in experimental design. Numerous in vitro and in vivo studies using diverse experimental systems have demonstrated that the growth, survival, polarity, and invasive behavior of breast cancer cells can be modulated by myoepithelial and various stromal cells, and several genes have been implicated to play an important role in this process $(6-13,22-26)$. In addition, certain histopathological features of breast tumors, including lymphocytic infiltration, fibrosis, and angio- and lymphangiogenesis, have proven prognostic significance. Despite these convincing data implicating a role for stromal cells in breast tumorigenesis, our understanding of the genes mediating cellular interactions and paracrine regulatory circuits among various cell types in normal and cancerous breast tissue and their role in breast tumorigenesis is limited.

As a consequence of studies focusing almost exclusively on cancer cells, nearly all of the currently used cancer therapeutic agents target the cancer cells that, due to their inherent genomic instability, frequently acquire therapeutic resistance (27). In part due to frequent therapeutic failures during the course of treatment of advanced stage tumors, increasing emphasis has been placed on targeting various stromal cells, particularly endothelial cells, via therapeutic interventions. Since these cells are thought to be normal and genetically stable, they are less likely to develop acquired resistance to cancer therapy. Thus, molecular targeting of the tumor microenvironment may be a novel promising option for cancer intervention and treatment.

Among all the cells types in the breast, myoepithelial cells have been one of the least analyzed, especially compared to luminal epithelial cells $(25,28)$. In this review we discuss the characteristics and normal function of myoepithelial cells and their putative role in breast tumor progression including the hypothesis that myoepithelial cells are the key regulators of the in situ to invasive carcinoma transition 
and may be part the stem cell niche. We mainly focus on the human mammary gland and breast carcinomas, although also reference studies using various model organisms.

\section{THE IDENTITY OF MYOEPITHELIAL CELLS}

The mammary gland is composed to multiple cell types including luminal and myoepithelial cells residing within the ducts and alveoli and various other cells located in the stroma. In the ducts myoepithelial cells form a nearly continuous layer of cells that surrounds the luminal epithelial cells and separates them from the basement membrane and the stroma, while in the alveoli myoepithelial cells form a scaffold like structure and some alveolar epithelial cells have direct contact with the basement membrane (Figure 1). Luminal epithelial and myoepithelial cells are differentiated using cell type specific markers, many of which have been only fortuitously identified following immunohistochemical analysis of breast tissue. Myoepithelial cell specific genes include smooth muscle actin (SMA), CD10/CALLA cell surface marker, calponin, cytokeratins 14 and 17 (CTK14 and CTK17), epidermal growth factor receptor (EGFR), and p63 (29-31). In recent years several genome-wide unbiased studies were performed using various cell purification and profiling approaches to better characterize normal luminal epithelial or myoepithelial cells and identify additional genes specific for a particular cell lineage (32-34). One of these studies analyzed established myoepithelial cell lines and xenografts using Affymetrix arrays and compared them to normal and cancerous breast cell lines and primary tumors (32). Using this approach the author identified numerous genes that distinguished myoepithelial cells from other cell types. Interestingly many of these genes encode for extracellular matrix proteins (collagens, laminin A, fibronectin, osteonectin, etc.), angiogenic (thrombospondin-1, plasminogen, etc.) and protease (maspin, PAI-1, etc.) inhibitors, re-confirming the role of myoepithelial cells as tumor suppressors (32). However, the gene expression profile of cell lines and xenografts may not faithfully reflect the in vivo patterns, therefore, profiling of uncultured cells is desirable for the discovery of cell lineage specific markers. Along these lines proteomic analysis of uncultured purified normal luminal and myoepithelial cells 
identified 170 proteins differentially expressed between the two cell types and 51 of these were annotated by tandem mass spectrometry (33). Many of these corresponded to abundant cytoplasmic proteins, such as cytokeratins, intermediate filaments, and heat shock proteins. Another gene expression profiling study used SAGE (Serial Analysis of Gene Expression) to analyze freshly isolated, uncultured luminal epithelial and myoepithelial cells purified using BerEP4 and CD10 antibody coupled magnetic beads, respectively, from normal breast tissue (34). This analysis revealed 295 genes statistically significantly

differentially expressed between the two cell types, and identified 138 that were more abundant in myoepithelial cells. Interestingly a high fraction (43\%) of the genes most highly specifically expressed in myoepithelial cells encode secreted or cell surface proteins suggesting that myoepithelial cells are actively involved in autocrine/paracrine interactions (Table 1).

All these studies assumed that there is only one type of myoepithelial cell within the normal breast, but this is unlikely to be true, since not all myoepithelial cells express all myoepithelial markers, and myoepithelial cells localized in the ducts and alveoli may also be different. Therefore, additional analyses are necessary to further define the molecular portrait of the various normal myoepithelial cells.

\section{THE ORIGIN OF MYOEPITHELIAL CELLS}

The cell or origin of normal myoepithelial cells is not well defined. Understanding the normal development of the mammary gland, clarifying the relationships among stem cells and their differentiated progeny, and characterizing factors regulating these processes are important not only for furthering our knowledge of basic mammary gland biology, but also for improving our understanding of breast tumorigenesis. Human epidemiologic data indicate that exposure to various hormones, radiation and other environmental agents during intrauterine, infantile, or pubertal mammary gland development influence the subsequent incidence of breast cancer in adulthood (35-38). The development of the mammary gland is a complex process and contrary to that of most other organs it is completed only in adulthood and some aspects of cellular differentiation even require the completion of a full-term pregnancy, lactation, and 
involution cycle. The mammary gland is also unique with respect to being continuously remodeled following puberty due to the cyclical influence of reproductive hormones. Most of our data on mammary gland development have been obtained in mice and interpreted for humans despite the well-known differences between human and mouse mammary gland development and function. Studies analyzing the development of the human mammary gland have been limited to structural and immunohistochemical analyses of a limited number of samples collected at different stages of fetal, infantile, childhood, and pubertal development (39-42). In the human embryo the breast bud arises as a result of proliferation of basal cells of the epidermis, and some markers of these basal keratinocytes are maintained (CTK19), while others are extinguished (CTK14) in the mammary epithelial cells potentially due to factors secreted by the mesenchymal cells present in the breast bud (40). Myoepithelial cell differentiation, as determined by the expression of myoepithelial cell specific markers (SMA, CD10, p63, etc.) and the lack of expression of luminal cell markers (CTK19 etc.) seems to occur at 21-28 weeks of gestational age (41, 42). However, not all markers characteristic for myoepithelial cells are expressed in the SMA positive basal cells of the fetal mammary gland, suggesting that the terminal differentiation of myoepithelial cells is a multi-step process and there may be several intermediary cells with varying stem cell potential and lineage commitment. This seems to the case even in breast tissue of adult women based on a recent immunohistochemical analysis of myoepithelial cell using multiple lineage specific markers (43). Specifically, a subset of morphologically myoepithelial appearing cells lack the expression of the nine cell lineage specific markers analyzed. However, it is possible that these cells are not truly differentiated myoepithelial cells, but bipotential or myoepithelial progenitor cells. Characterization of mammary stem cells and identification of stem cells specific markers would be necessary to conclusively answer this question.

Almost nothing is known about the identity of factors that regulate myoepithelial cell differentiation, although recent data indicate the involvement of the Notch pathway $(44,45)$. Specifically, activation of the Notch pathway not only appears to enhance the proliferation of the putative mammary 
stem cells, but also increases the number of cells committed to the myoepithelial lineage by promoting the proliferation of bipotential or myoepithelial progenitor cells and enhancing myoepithelial differentiation. Further studies are needed to identify and characterize regulators of mammary stem cell proliferation and differentiation and determine how abnormal activity of these pathways may contribute to breast tumorigenesis.

\section{THE FUNCTION OF MYOEPITHELIAL CELLS IN BREAST TUMOR PROGRESSION}

Breast tumors evolve via sequential progression through defined clinical and pathologic stages starting with ductal epithelial hyperproliferation, progressing into in situ then invasive, and metastatic carcinomas. DCIS is believed to be the true precursor of invasive ductal carcinoma based on molecularbased clonality studies, its increased incidence in women with high risk of invasive breast cancer, its frequent coexistence with invasive lesions, and on its high rate of recurrence as an invasive tumor at its original site (46-52). Until 1980, DCIS was diagnosed very rarely and represented less than $1 \%$ of all breast cancer cases. Due to the increased use of mammograms DCIS became the most rapidly increasing subset of breast cancers and currently it accounts for $15-25 \%$ of newly diagnosed breast cancer cases in the United States $(53,54)$. In contrast to the dramatic improvement in our ability to detect DCIS, our understanding of the pathophysiology of this disease and factors involved in its progression to invasive carcinoma are still poorly defined.

The major diagnostic criteria that pathologists use to differentiate in situ from invasive carcinomas is the presence or absence of an intact myoepithelial cell layer, which is usually confirmed by performing immunohistochemical analyses against myoepithelial cell specific genes such as smooth muscle actin, p63, or CD10 (55). However, it is unknown what leads to the disappearance of the myoepithelial cells in invasive tumors (selective elimination by apoptosis or lack of proper myoepithelial cells differentiation from stem cells) and how this contributes to tumor progression. Exposure of myoepithelial cells in culture to even low concentrations of carrageenans, naturally occurring sulfated polysaccharides used in 
commercial food preparation, leads to cell death (56). However, it is unknown if destruction of myoepithelial cells could occur by these compounds or by other environmental agents in human breast cancer patients.

\section{The tumor suppressor function of myoepithelial cells}

Myoepithelial cells have been called natural tumor suppressors due to their negative effect on various neoplastic phenotypes including tumor cell growth, invasion, and angiogenesis (23-25, 28). Myoepithelial cells also synthesize the basement membrane of the ducts and alveoli and form a structural barrier between the luminal epithelial cells and the surrounding stroma, thus, physically preventing tumor cell invasion. The tumor suppressor phenotype was determined based on the ability of myoepithelial cells to inhibit the growth and invasion of breast cancer cells in co-culture assays in vitro and inhibit tumor growth in xenograft assays $(23,24,57,58)$. These effects have been largely attributed to paracrine factors secreted by myoepithelial cells that exert their effects on the tumor epithelial cells. Some of these factors include ECM proteins, protease inhibitors, various growth factors, and some are still unidentified. Most of these studies were performed using myoepithelial cell lines derived from benign or low-grade human myoepitheliomas of the breast, salivary gland, and bronchi, thus, these cells may no completely reflect the function of normal mammary epithelial cells (59). However, the myoepithelial cell lines used in these experiments are genetically fairly normal, have maintained the expression of all myoepithelial markers analyzed (SMA, S100A2, CTK14, etc.) even after prolonged passage in vitro, and the expression of all anti-tumorigenic genes was confirmed in primary human breast tissue by immunohistochemistry. In addition, the results were reproduced using freshly isolated primary normal mammary myoepithelial cells (60). In these experiments co-culturing normal breast myoepithelial cells (purified using antiCD10/CALLA antibody) using transwell insert with various human breast cancer cell lines led to decreased expression of MMPs (Matrix Metallo-proteases) in the cancer cells. This effect of the 
myoepithelial cells was observed even in the presence of co-cultured fibroblasts, known promoters of tumor cell invasion, thus, demonstrating the dominance of myoepithelial cells.

The anti-invasive and anti-proliferative effects of myoepithelial cells can be further increased following treatment with tamoxifen due to the increased secretion of maspin and production of inducible nitric oxide synthase (iNOS) and these effects are mediated by the estrogen receptor (61). Although myoepithelial cells do not express estrogen receptor- $\alpha(\mathrm{ER} \alpha)$ they express $\mathrm{ER} \beta$ both in vitro and in vivo $(61,62)$ and the induction of maspin and iNOS appears to be mediated by ER $\beta$ dependent activation of AP1. It remains to be determined if this effect of tamoxifen is also observed in breast cancer patients and if it contributes to the cancer preventative effects of anti-estrogens.

In addition to being responsive to tamoxifen mammary epithelial cells may also influence the response of luminal epithelial cells to estrogenic hormones, since they express high levels of steroid sulfatase (STS), a lysosomal hydrolyse that converts estrone 3-sulfate (E1S) and dehydroepiandrosteronesulfate (DHEA-S) into their active, unsulfated forms (63). The expression of STS in the myoepithelial cells may lead to increased local concentration of these hormones making them available for the ER $\alpha$ luminal epithelial cells. However, this result has not been confirmed in vivo, thus, the potential role of myoepithelial cells as regulators of the local concentration of estrogenic hormones remains to be determined.

Myoepithelial cells also influence the differentiation and polarity of the adjacent luminal epithelial cells. Luminal epithelial cells are polarized as determined by the expression of sialomucin, epithelial specific antigen (ESA), and occludin on the luminal membrane and integrin $\beta 4$ on the basolateral membrane. This polarity is observed in vitro when luminal epithelial cells are cultured in reconstituted basement membrane (matrigel), but lost when the cells are grown in collagen I (22). However, mixing the luminal epithelial cells with normal myoepithelial cells was able to restore epithelial cell polarity even in collagen cultures, and this effect was shown to be mediated by laminin-1. Interestingly myoepithelial cells 
isolated from invasive breast tumors were unable to exert this effect (22). These tumor myoepithelial cells were isolated from primary breast carcinomas using a Thy-1 antibody column and they were considered myoepithelial cells due to their emergence from luminal epithelial cells, expression of cytokeratins, vimentin, and SMA, and inability to form tumors in nude mice, but they were not analyzed for genetic changes and clonal relationship to the epithelial cells from the same tumor. Invasive breast tumors by definition devoid of myoepithelial cells, but a subset of tumor cells, including the presumable 'cancer stem cells", express high levels of Thy-1, vimentin, and cytokeratins. Similarly, stromal myofibroblasts are highly Thy-1 and vimentin positive, although lack cytokeratins. Thus, the identity of these tumor myoepithelial cells is somewhat of a mystery and would require further studies, although it is clear that they are not able to recapitulate the function of normal myoepithelial cells presumably due to their lack of laminin-1 expression.

\section{Alterations in myoepithelial and stromal cells during breast tumor progression}

In the past few years the role of the cellular microenvironment in tumorigenesis has become an intense area of research. This is in part due to studies demonstrating that genetic abnormalities, such as loss of heterozygosity ( $\mathrm{LOH})$, occur not only in cancer cells, but in myoepithelial or stromal cells, or even normal appearing epithelial cells surrounding the tumor and in benign stromal and epithelial hyperproliferative diseases (64-72). In several cases the tumor epithelial and stromal cells had discordant

genetic changes suggesting a clonal co-evolution for these two cell types. Due to the low probability of two adjacent cells simultaneously acquiring different genetic changes, the authors suggested that in some breast tumors cancer epithelial and stromal cells may be derived from a common stem cell, but subsequently undergo divergent genetic selection processes. One study demonstrated discordant mutations in TP53 and PTEN in tumor epithelial and stromal cells, and low frequency of WFDC1 mutations exclusively in the stromal cells (67). However, no mechanistic insight was provided explaining the clonal selection for mutation in the same gene in the two different cellular compartments. Thus, the 
biological relevance of these mutations and $\mathrm{LOH}$ events in stromal cells and their role in breast tumorigenesis is still largely unknown. One potential problem with these studies is that the cellular identity of the stromal cells was not conclusively confirmed (e.g. by cell type specific markers), and since they were isolated using LCM (laser capture microdissection) from formalin fixed and paraffin embedded or frozen breast tumors, the possibility of contaminating tumor cells is difficult to rule out. Furthermore, due to the methods used relatively few stromal cells were analyzed and from a relatively small area of the tumor. Thus, it is uncertain if these $\mathrm{LOH}$ events reflect true clonally selected genetic events that are observed in the majority of the tumor stroma or they are just random LOH that occur at low frequency in every dividing cell. Similarly the report describing LOH in normal luminal and myoepithelial cells obtained from reduction mammoplasty specimens analyzed clones of cells expanded in in vitro cultures (73). Thus, the possibility that the clone of a single cell expanded in vitro was analyzed or that the $\mathrm{LOH}$ occurred in vitro cannot e excluded.

Immunohistochemical analyses of normal breast tissue and in situ and invasive breast carcinomas aiming to identify markers of tumor progression using a candidate gene approach have identified several genes that are differentially expressed between normal and DCIS myoepithelial cells. Among others lysyl oxidase, an enzyme involved in collagen and elastin crosslinking, was most highly expressed in myoepithelial cells and myofibroblasts in DCIS tumors (74). Similarly the expression of neuropilin-1 was found to be up-regulated in DCIS myoepithelial and vascular smooth muscle cells compared to normal breast tissue and invasive carcinomas (75). To identify molecular changes in the cellular microenvironment in an unbiased way, $\mathrm{Hu}$ et al. purified and analyzed all cell types (epithelial, myoepithelial, and endothelial cells, infiltrating leukocytes, fibroblasts and myofibroblasts) from normal breast tissue, and in situ and invasive carcinomas, and concluded that gene expression changes occur in all cell types during breast tumor progression, but clonally selected genetic changes are only observed in tumor epithelial cells (76). In this study each cell type was purified using cell type specific cell surface markers and the purity of the isolated cell population was confirmed using RT-PCR and cell type specific 
genes. The comprehensive gene expression profile of each purified cell population was then analyzed by SAGE (Serial Analysis of Gene Expression), while genetic changes were analyzed by cDNA array CGH (Comprehensive Genomic Hybridization) and SNP (Single Nucleotide Polymorphism) arrays. Interestingly the comparison of myoepithelial cells from normal breast tissue and DCIS yielded the highest number of consistently differentially expressed genes, and a significant fraction of these encoded for secreted and cell surface proteins including several chemokines (Tables 1 and 2). Many of the genes specific for normal myoepithelial cells (CTK14, CTK17, OXTR, EGFR, etc.) were absent or dramatically downregulated in DCIS myoepithelial cells suggesting that myoepithelial cells in DCIS are not really "normal" since they appear to be less differentiated and likely have lost some of the functions of normal myoepithelial cells (Tables 1 and 2). However, demonstrating functional differences between normal and DCIS myoepithelial cells and demonstrating that these changes play a role in breast tumor progression require further studies.

The dramatic gene expression changes and lack of genetic alterations in the myoepithelial and stromal cells suggested underlying epigenetic changes, since cells isolated from normal and tumor tissue are known to maintain their differences even after prolonged cell culture in vitro $(8,13,77,78)$. Indeed, a follow up study by the same group using a newly developed method (MSDK-Methylation Specific Digital Karyotyping) for the analysis of genome-wide methylation profiles identified alterations in DNA methylation patterns not only in tumor epithelial cells, but in stromal fibroblasts and DCIS myoepithelial cells as well (79). Consistent with prior results, increased DNA methylation in the promoter region of the genes negatively correlated with gene expression, while hypermethylation of introns and $3^{\prime}$ exons positively influenced gene expression suggesting the presence of silencer elements that are regulated by DNA methylation $(79,80)$. The best characterized example for this is the imprinting of the H19/IGF2 genes that is regulated by a silencer containing a binding site for CTCF $(81,82)$. The imprinting of IGF2 is dependent on CTCF binding to this enhancer-blocking element and its methylation inhibits CTCF binding and leads to loss of imprinting $(81,82)$. Interestingly based on their sequence two of the 
differentially methylated genes identified by $\mathrm{Hu}$ et al. appear to have a CTCF binding site in their hypermethylated region, but demonstrating their silencer function requires follow up studies.

\section{The relationship between myoepithelial cells and myofibroblasts}

Close "relatives" of myoepithelial cells of myoepithelial cells are the myofibroblasts, since they share the expression of many genes including SMA, Thy-1, vimentin, CD10/CALLA, and several proteases and protease inhibitors (76). However, myoepithelial cells express cytokeratins and are located within the breast ducts, while myofibroblasts are mesenchymal cells located in the stroma. The cell of origin of myofibroblasts is still subject to debate with two main hypotheses dominating. According to one model myofibroblasts are fibroblasts "transformed" by TGF $\beta$ and PDGF potentially secreted by the tumor cells or infiltrating leukocytes, since treatment of fibroblasts in in vitro cultures with these growth factors leads to the expression of SMA and other myofibroblast specific genes $(83,84)$. However, in vivo studies performed both in mice and human provide strong evidence that myofibroblasts are derived from circulating mesenchymal stem cells recruited to the tumors either by the tumor cells themselves or by the inflammatory reaction initiated by infiltrating leukocytes $(85,86)$. Despite the similarity of gene expression patterns between myoepithelial cells and myofibroblasts, it is unlikely that the two cell types

are clonally related. Correlating with this comprehensive analysis of their gene expression profiles identified many genes differentially expressed between the two cell types (Table 2). A significant fraction (49\%) of these genes encode secreted and cell surface proteins including chemokines, ECM molecules, proteases and protease inhibitors, implicating both cells in autocrine/paracrine interactions and ECM remodeling. The hypothesis that myoepithelial cells may become myofibroblasts during the in situ to invasive carcinoma transition is unlikely, but deserves further investigation.

\section{Models of breast tumor progression}


Our fairly limited understanding of in situ to invasive carcinoma transition is in part due to the fact that there are no good experimental models for DCIS that would faithfully reproduce the human disease. Carcinogen induced mammary gland tumors in rats reproduce certain aspects of human DCIS, such as ovarian hormone dependence and gradual progression to invasive disease(87). However, the carcinogen used for the initiation of these tumors may have caused numerous genetic changes that are not easy to identify making this model unattractive for molecular studies addressing the role of specific genes in mammary tumorigenesis. The same limitation applies to the use of DCIS xenografts formed by subcutaneous injection of pieces of human DCIS tumors into nude mice(88).

Although no model is ideal, they allow the functional testing of genes implicated in breast cancer and the evaluation of novel cancer preventative and therapeutic interventions. A good model of DCIS would have to resemble the histology of high-risk human pre-malignant breast lesion that with time progress to invasive carcinomas. The MCF10AT human breast cell line is one of the most well characterized human models of breast tumor progression that fulfills these criteria $(89,90)$. These cells were derived from the immortalized MCF-10A cells via transformation with T24 mutant c-Ha-ras (89, 90). Interestingly, the MCF10AT cells appear to contain multi-potent (or bipotential) breast stem cells, since both luminal epithelial and myoepithelial cells can be derived from these cells in vivo(91). Recently a derivative of the MCF10AT premalignant human cell line model was established MCF10DCIS.com that reproducibly forms comedo DCIS like lesions that spontaneously progress to invasive tumors $(89,90)$. However, just because a tumor looks like a DCIS it does not mean that it is "really" a DCIS and cells expressing myoepithelial markers may not always be "real" myoepithelial cells. This is illustrated by the detection of "revertant" DCIS in lymph nodes of some breast cancer patients with metastatic breast tumors (92). Specifically, a subset of invasive or metastatic breast tumors demonstrate a DCIS-like growth pattern as determined by cells growing in tight clusters surrounded by basement membrane, but these structures lack a myoepithelial cell layer emphasizing the importance of staining for myoepithelial cell specific markers in cases of questionable diagnosis. Similarly, in invasive breast tumors with basal phenotype the tumor 
cells themselves express several genes normally detected in myoepithelial cells including p63 and cytokeratin 14, presumably because these tumors originate from bipotential progenitor cells and show some degree of myoepithelial differentiation, but they never express smooth muscle actin (93). Thus, to conclusively prove that a cell is a normal terminally differentiated myoepithelial cell the examination of multiple markers is necessary.

\section{The "escape" or "release" model of in situ to invasive carcinoma transition}

The prevailing view of breast tumor progression is tumor epithelial cell driven, since tumor epithelial cells have acquired genetic changes and demonstrate genomic instability, and thus, the most aggressive invasive cells can be selected out due to clonal selection. However, this model has recently been challenged by multiple independent studies. First, demonstrating genetic changes in tumor stroma, although still controversial, raises the possibility that clonal selection occurs in non-epithelial cells as well, thus, the microenvironment may play an active role in driving tumor progression. Second, demonstrating global gene expression and epigenetic alterations in all cell types during breast tumor progression and the finding that the genetic background of the host influences metastatic behavior suggest that tumorigenesis is a "teamwork" and although genetic changes may only occur in tumor epithelial cells, changes in the cellular microenvironment are likely to play a role in tumor progression. Studies demonstrating increased cancer risk in patients with chronic inflammatory disease and decreased risk in

users of anti-inflammatory drugs, and experiments performed in model systems addressing the role of genetically modified stroma in tumorigenesis, even raise the possibility that alterations in the microenvironment play a role in tumor initiation.

Based on these data we propose two alternative models of the in situ to invasive carcinoma transition (Figure 3). One hypothesis emphasizes the role of tumor epithelial cells and suggests that genetic changes in these cells lead to the selection of a clone with invasive properties that will "escape" from the duct, spread into the stroma, and subsequently expand. The second model gives more credit to 
the non-epithelial cells and implies that phenotypic changes in DCIS myoepithelial cells, accumulation of inflammatory cells and myofibroblasts work together and lead to the break down of the ducts and results in the "release" of tumor epithelial cells. Recently published studies describing focal myoepithelial cell layer disruption in DCIS breast tumors at sites of leukocytic infiltration gives support to the "release" model (94). Similarly experiments performed using the MCF10DCIS.com model system suggest that myoepithelial cells play a key role in the regulation of in situ to invasive carcinoma transition (Hu et al. unpublished data). However, the two models are not mutually exclusive. For example, it is possible that factors secreted by DCIS myoepithelial cells, infiltrating leukocytes and myofibroblasts may influence the clonal evolution of the tumor epithelial cells. Supporting this combined view is the finding that tumor epithelial cells overlaying sites of focally disrupted myoepithelial cell layers are phenotypically and genetically different from their adjacent counterparts (94). Since presumably these are the cells responsible for the subsequent progression of the tumors, thus, presumably are the putative "cancer stem cells", this raises the question if paracrine factors secreted by myoepithelial and stromal cells may influence the cancer stem cell phenotype. Thus, in a way cells of the tumor microenvironment may constitute the stem cell niche, a hypothesis worth investigating in the future. Of course it is difficult to know what comes first, the development of a genetically distinct tumor epithelial cell clone or the myoepithelial cell layer disruption. Clarifying this "chicken or egg" dilemma will likely to keep investigators busy for years to come.

\section{CONCLUSIONS}

Due to decades of neglect the function of mammary myoepithelial cells and their role in breast tumorigenesis is still largely unknown. However, recent and emerging studies implicate them as potential regulators of in situ to invasive carcinoma transition and stem cell function. In light of the importance of these issues, myoepithelial cells are now the focus of intense investigations and via understanding their function we are likely to gain new, valuable targets for breast cancer prevention and treatment. 


\section{ACKNOWLEDGEMENTS}

We greatly appreciate the generosity of Drs. Andrea Richardson and Stuart Schnitt for providing images and slides of immunohistochemical analyses depicted in Figures 1 and 2. The authors thank Drs. Myles Brown, Craig Allred, and Ian Krop for useful discussions and their critical reading of this manuscript. The authors are supported by grants from the National Institute of Health (P50 CA89393-05 and CA9407403), Department of Defense (DAMD17-02-1-0692 and W8IXWH-04-1-0452), and American Cancer Society (RSG-05-154-01-MGO). 


\section{REFERENCES}

1. Sorlie T, Perou CM, Tibshirani R, Aas T, Geisler S, Johnsen H, et al. Gene expression patterns of breast carcinomas distinguish tumor subclasses with clinical implications. Proc Natl Acad Sci U S A 2001;98(19):10869-74.

2. van 't Veer LJ, Dai H, van de Vijver MJ, He YD, Hart AA, Bernards R, et al. Expression profiling predicts outcome in breast cancer. Breast Cancer Res 2002;5(1):57-8.

3. van 't Veer LJ, Dai H, van de Vijver MJ, He YD, Hart AA, Mao M, et al. Gene expression profiling predicts clinical outcome of breast cancer. Nature 2002;415(6871):530-6.

4. van de Vijver MJ, He YD, van't Veer LJ, Dai H, Hart AA, Voskuil DW, et al. A gene-expression signature as a predictor of survival in breast cancer. N Engl J Med 2002;347(25):1999-2009.

5. Ramaswamy S, Ross KN, Lander ES, Golub TR. A molecular signature of metastasis in primary solid tumors. Nat Genet 2003;33(1):49-54.

6. Shekhar MP, Pauley R, Heppner G. Host microenvironment in breast cancer development: extracellular matrix-stromal cell contribution to neoplastic phenotype of epithelial cells in the breast. Breast Cancer Res 2003;5(3):130-5.

7. Kenny PA, Bissell MJ. Tumor reversion: correction of malignant behavior by microenvironmental cues. Int J Cancer 2003;107(5):688-95.

8. Bissell MJ, Radisky DC, Rizki A, Weaver VM, Petersen OW. The organizing principle: microenvironmental influences in the normal and malignant breast. Differentiation 2002;70(9-10):537-46.

9. Radisky D, Hagios C, Bissell MJ. Tumors are unique organs defined by abnormal signaling and context. Semin Cancer Biol 2001;11(2):87-95.

10. Coussens LM, Werb Z. Inflammation and cancer. Nature 2002;420(6917):860-7.

11. Wiseman BS, Werb Z. Stromal effects on mammary gland development and breast cancer. Science 2002;296(5570):1046-9.

12. Tlsty TD. Stromal cells can contribute oncogenic signals. Semin Cancer Biol 2001;11(2):97-104. 
13. Tlsty TD, Hein PW. Know thy neighbor: stromal cells can contribute oncogenic signals. Curr Opin Genet Dev 2001;11(1):54-9.

14. DeCosse JJ, Gossens CL, Kuzma JF, Unsworth BR. Breast cancer: induction of differentiation by embryonic tissue. Science 1973;181(104):1057-8.

15. DeCosse JJ, Gossens C, Kuzma JF, Unsworth BR. Embryonic inductive tissues that cause histologic differentiation of murine mammary carcinoma in vitro. J Natl Cancer Inst 1975;54(4):913-22.

16. Rohan RM, Fernandez A, Udagawa T, Yuan J, D'Amato RJ. Genetic heterogeneity of angiogenesis in mice. Faseb J 2000;14(7):871-6.

17. Hunter KW. Host genetics and tumour metastasis. Br J Cancer 2004;90(4):752-5.

18. Bhowmick NA, Chytil A, Plieth D, Gorska AE, Dumont N, Shappell S, et al. TGF-beta signaling in fibroblasts modulates the oncogenic potential of adjacent epithelia. Science 2004;303(5659):848-51.

19. Cheng N, Bhowmick NA, Chytil A, Gorksa AE, Brown KA, Muraoka R, et al. Loss of TGF-beta type II receptor in fibroblasts promotes mammary carcinoma growth and invasion through upregulation of TGF-alpha-, MSP- and HGF-mediated signaling networks. Oncogene 2005;24(32):5053-68.

20. Maffini MV, Soto AM, Calabro JM, Ucci AA, Sonnenschein C. The stroma as a crucial target in rat mammary gland carcinogenesis. J Cell Sci 2004;Pt.

21. Medina D, Kittrell F. Stroma is not a major target in DMBA-mediated tumorigenesis of mouse mammary preneoplasia. J Cell Sci 2005;118(Pt 1):123-7.

22. Gudjonsson T, Ronnov-Jessen L, Villadsen R, Rank F, Bissell MJ, Petersen OW. Normal and tumor-derived myoepithelial cells differ in their ability to interact with luminal breast epithelial cells for polarity and basement membrane deposition. J Cell Sci 2002;115(Pt 1):39-50.

23. Sternlicht MD, Barsky SH. The myoepithelial defense: a host defense against cancer. Med Hypotheses 1997;48(1):37-46.

24. Sternlicht MD, Kedeshian P, Shao ZM, Safarians S, Barsky SH. The human myoepithelial cell is a natural tumor suppressor. Clin Cancer Res 1997;3(11):1949-58. 
25. Deugnier MA, Teuliere J, Faraldo MM, Thiery JP, Glukhova MA. The importance of being a myoepithelial cell. Breast Cancer Res 2002;4(6):224-30.

26. Elenbaas B, Weinberg RA. Heterotypic signaling between epithelial tumor cells and fibroblasts in carcinoma formation. Exp Cell Res 2001;264(1):169-84.

27. Rajagopalan H, Nowak MA, Vogelstein B, Lengauer C. The significance of unstable chromosomes in colorectal cancer. Nat Rev Cancer 2003;3(9):695-701.

28. Lakhani SR, O'Hare MJ. The mammary myoepithelial cell--Cinderella or ugly sister? Breast Cancer Res 2001;3(1):1-4.

29. Barbareschi M, Pecciarini L, Cangi MG, Macri E, Rizzo A, Viale G, et al. p63, a p53 homologue, is a selective nuclear marker of myoepithelial cells of the human breast. Am J Surg Pathol 2001;25(8):1054-60.

30. Santini D, Ceccarelli C, Tardio ML, Taffurelli M, Marrano D. Immunocytochemical expression of epidermal growth factor receptor in myoepithelial cells of the breast. Appl Immunohistochem Mol Morphol 2002;10(1):29-33.

31. Yaziji H, Gown AM, Sneige N. Detection of stromal invasion in breast cancer: the myoepithelial markers. Adv Anat Pathol 2000;7(2):100-9.

32. Barsky SH. Myoepithelial mRNA expression profiling reveals a common tumor-suppressor phenotype. Exp Mol Pathol 2003;74(2):113-22.

33. Page MJ, Amess B, Townsend RR, Parekh R, Herath A, Brusten L, et al. Proteomic definition of normal human luminal and myoepithelial breast cells purified from reduction mammoplasties. Proc Natl Acad Sci U S A 1999;96(22):12589-94.

34. Porter DA, Krop IE, Nasser S, Sgroi D, Kaelin CM, Marks JR, et al. A SAGE (serial analysis of gene expression) view of breast tumor progression. Cancer Res 2001;61(15):5697-702.

35. Baik I, Becker PS, DeVito WJ, Lagiou P, Ballen K, Quesenberry PJ, et al. Stem cells and prenatal origin of breast cancer. Cancer Causes Control 2004;15(5):517-30. 
36. Trichopoulos D. Intrauterine environment, mammary gland mass and breast cancer risk. Breast Cancer Res 2003;5(1):42-4.

37. Clemons M, Loijens L, Goss P. Breast cancer risk following irradiation for Hodgkin's disease. Cancer Treat Rev 2000;26(4):291-302.

38. Hildreth NG, Shore RE, Dvoretsky PM. The risk of breast cancer after irradiation of the thymus in infancy. N Engl J Med 1989;321(19):1281-4.

39. Osin PP, Anbazhagan R, Bartkova J, Nathan B, Gusterson BA. Breast development gives insights into breast disease. Histopathology 1998;33(3):275-83.

40. Anbazhagan R, Osin PP, Bartkova J, Nathan B, Lane EB, Gusterson BA. The development of epithelial phenotypes in the human fetal and infant breast. J Pathol 1998;184(2):197-206.

41. Naccarato AG, Viacava P, Vignati S, Fanelli G, Bonadio AG, Montruccoli G, et al. Biomorphological events in the development of the human female mammary gland from fetal age to puberty. Virchows Arch 2000;436(5):431-8.

42. Jolicoeur F, Gaboury LA, Oligny LL. Basal cells of second trimester fetal breasts: immunohistochemical study of myoepithelial precursors. Pediatr Dev Pathol 2003;6(5):398-413.

43. Zhang RR, Man YG, Vang R, Saenger JS, Barner R, Wheeler DT, et al. A subset of morphologically distinct mammary myoepithelial cells lacks corresponding immunophenotypic markers. Breast Cancer Res 2003;5(5):R151-6.

44. Dontu G, Jackson KW, McNicholas E, Kawamura MJ, Abdallah WM, Wicha MS. Role of Notch signaling in cell-fate determination of human mammary stem/progenitor cells. Breast Cancer Res 2004;6(6):R605-15.

45. Dontu G, Abdallah WM, Foley JM, Jackson KW, Clarke MF, Kawamura MJ, et al. In vitro propagation and transcriptional profiling of human mammary stem/progenitor cells. Genes Dev 2003;17(10):1253-70. 
46. Hoogerbrugge N, Bult P, de Widt-Levert LM, Beex LV, Kiemeney LA, Ligtenberg MJ, et al. High prevalence of premalignant lesions in prophylactically removed breasts from women at hereditary risk for breast cancer. J Clin Oncol 2003;21(1):41-5.

47. Adem C, Jenkins RB, Capron F, Stoppa-Lyonnet D. High-risk lesions in high-risk women: a highrisk formalin-based biology! J Clin Oncol 2004;22(6):1159-61; author reply 1161-2.

48. James LA, Mitchell EL, Menasce L, Varley JM. Comparative genomic hybridisation of ductal carcinoma in situ of the breast: identification of regions of DNA amplification and deletion in common with invasive breast carcinoma. Oncogene 1997;14(9):1059-65.

49. Waldman FM, DeVries S, Chew KL, Moore DH, 2nd, Kerlikowske K, Ljung BM. Chromosomal alterations in ductal carcinomas in situ and their in situ recurrences. J Natl Cancer Inst 2000;92(4):313-20. 50. Aubele M, Mattis A, Zitzelsberger H, Walch A, Kremer M, Welzl G, et al. Extensive ductal carcinoma In situ with small foci of invasive ductal carcinoma: evidence of genetic resemblance by CGH. Int J Cancer 2000;85(1):82-6.

51. Simpson PT, Reis-Filho JS, Gale T, Lakhani SR. Molecular evolution of breast cancer. J Pathol $2005 ; 205(2): 248-54$.

52. Leonard GD, Swain SM. Ductal carcinoma in situ, complexities and challenges. J Natl Cancer Inst 2004;96(12):906-20.

53. Li CI, Daling JR, Malone KE. Age-specific incidence rates of in situ breast carcinomas by histologic type, 1980 to 2001. Cancer Epidemiol Biomarkers Prev 2005;14(4):1008-11.

54. Burstein HJ, Polyak K, Wong JS, Lester SC, Kaelin CM. Ductal carcinoma in situ of the breast. N Engl J Med 2004;350(14):1430-41.

55. Damiani S, Ludvikova M, Tomasic G, Bianchi S, Gown AM, Eusebi V. Myoepithelial cells and basal lamina in poorly differentiated in situ duct carcinoma of the breast. An immunocytochemical study. Virchows Arch 1999;434(3):227-34. 
56. Tobacman JK. Filament disassembly and loss of mammary myoepithelial cells after exposure to lambda-carrageenan. Cancer Res 1997;57(14):2823-6.

57. Nguyen M, Lee MC, Wang JL, Tomlinson JS, Shao ZM, Alpaugh ML, et al. The human myoepithelial cell displays a multifaceted anti-angiogenic phenotype. Oncogene 2000;19(31):3449-59.

58. Shao ZM, Nguyen M, Alpaugh ML, O'Connell JT, Barsky SH. The human myoepithelial cell exerts antiproliferative effects on breast carcinoma cells characterized by $\mathrm{p} 21 \mathrm{WAF} 1 / \mathrm{CIP} 1$ induction, G2/M arrest, and apoptosis. Exp Cell Res 1998;241(2):394-403.

59. Sternlicht MD, Safarians S, Calcaterra TC, Barsky SH. Establishment and characterization of a novel human myoepithelial cell line and matrix-producing xenograft from a parotid basal cell adenocarcinoma. In Vitro Cell Dev Biol Anim 1996;32(9):550-63.

60. Jones JL, Shaw JA, Pringle JH, Walker RA. Primary breast myoepithelial cells exert an invasionsuppressor effect on breast cancer cells via paracrine down-regulation of MMP expression in fibroblasts and tumour cells. J Pathol 2003;201(4):562-72.

61. Shao ZM, Radziszewski WJ, Barsky SH. Tamoxifen enhances myoepithelial cell suppression of human breast carcinoma progression in vitro by two different effector mechanisms. Cancer Lett 2000;157(2):133-44.

62. Chi A, Chen X, Chirala M, Younes M. Differential expression of estrogen receptor beta isoforms in human breast cancer tissue. Anticancer Res 2003;23(1A):211-6.

63. Tobacman JK, Hinkhouse M, Khalkhali-Ellis Z. Steroid sulfatase activity and expression in mammary myoepithelial cells. J Steroid Biochem Mol Biol 2002;81(1):65-8.

64. Lakhani SR, Jacquemier J, Sloane JP, Gusterson BA, Anderson TJ, van de Vijver MJ, et al. Multifactorial analysis of differences between sporadic breast cancers and cancers involving BRCA1 and BRCA2 mutations. J Natl Cancer Inst 1998;90(15):1138-45. 
65. Kurose K, Hoshaw-Woodard S, Adeyinka A, Lemeshow S, Watson PH, Eng C. Genetic model of multi-step breast carcinogenesis involving the epithelium and stroma: clues to tumour-microenvironment interactions. Hum Mol Genet 2001;10(18):1907-13.

66. Moinfar F, Man YG, Arnould L, Bratthauer GL, Ratschek M, Tavassoli FA. Concurrent and independent genetic alterations in the stromal and epithelial cells of mammary carcinoma: implications for tumorigenesis. Cancer Res 2000;60(9):2562-6.

67. Kurose K, Gilley K, Matsumoto S, Watson PH, Zhou XP, Eng C. Frequent somatic mutations in PTEN and TP53 are mutually exclusive in the stroma of breast carcinomas. Nat Genet 2002;32(3):355-7.

68. Larson PS, de las Morenas A, Bennett SR, Cupples LA, Rosenberg CL. Loss of heterozygosity or allele imbalance in histologically normal breast epithelium is distinct from loss of heterozygosity or allele imbalance in co-existing carcinomas. Am J Pathol 2002;161(1):283-90.

69. Deng G, Lu Y, Zlotnikov G, Thor AD, Smith HS. Loss of heterozygosity in normal tissue adjacent to breast carcinomas. Science 1996;274(5295):2057-9.

70. Fukino K, Shen L, Matsumoto S, Morrison CD, Mutter GL, Eng C. Combined total genome loss of heterozygosity scan of breast cancer stroma and epithelium reveals multiplicity of stromal targets. Cancer Res 2004;64(20):7231-6.

71. Dietrich CU, Pandis N, Teixeira MR, Bardi G, Gerdes AM, Andersen JA, et al. Chromosome abnormalities in benign hyperproliferative disorders of epithelial and stromal breast tissue. Int $\mathrm{J}$ Cancer 1995;60(1):49-53.

72. Iqbal M, Shoker BS, Foster CS, Jarvis C, Sibson DR, Davies MP. Molecular and genetic abnormalities in radial scar. Hum Pathol 2002;33(7):715-22.

73. Lakhani SR, Chaggar R, Davies S, Jones C, Collins N, Odel C, et al. Genetic alterations in 'normal' luminal and myoepithelial cells of the breast. J Pathol 1999;189(4):496-503. 
74. Peyrol S, Raccurt M, Gerard F, Gleyzal C, Grimaud JA, Sommer P. Lysyl oxidase gene expression in the stromal reaction to in situ and invasive ductal breast carcinoma. Am $\mathrm{J}$ Pathol 1997;150(2):497-507.

75. Stephenson JM, Banerjee S, Saxena NK, Cherian R, Banerjee SK. Neuropilin-1 is differentially expressed in myoepithelial cells and vascular smooth muscle cells in preneoplastic and neoplastic human breast: a possible marker for the progression of breast cancer. Int J Cancer 2002;101(5):409-14.

76. Allinen M, Beroukhim R, Cai L, Brennan C, Lahti-Domenici J, Huang H, et al. Molecular characterization of the tumor microenvironment in breast cancer. Cancer Cell 2004;6(1):17-32.

77. Bissell MJ, Radisky D. Putting tumours in context. Nat Rev Cancer 2001;1(1):46-54.

78. Orimo A, Gupta PB, Sgroi DC, Arenzana-Seisdedos F, Delaunay T, Naeem R, et al. Stromal fibroblasts present in invasive human breast carcinomas promote tumor growth and angiogenesis through elevated SDF-1/CXCL12 secretion. Cell 2005;121(3):335-48.

79. Hu M, Yao J, Cai L, Bachman KE, van den Brule F, Velculescu V, et al. Distinct epigenetic changes in the stromal cells of breast cancers. Nat Genet 2005.

80. Ushijima T. Detection and interpretation of altered methylation patterns in cancer cells. Nat Rev Cancer 2005;5(3):223-31.

81. Feinberg AP, Tycko B. The history of cancer epigenetics. Nat Rev Cancer 2004;4(2):143-53.

82. Bell AC, Felsenfeld G. Methylation of a CTCF-dependent boundary controls imprinted expression of the Igf2 gene. Nature 2000;405(6785):482-5.

83. Shao ZM, Nguyen M, Barsky SH. Human breast carcinoma desmoplasia is PDGF initiated. Oncogene 2000;19(38):4337-45.

84. Ronnov-Jessen L, Petersen OW, Koteliansky VE, Bissell MJ. The origin of the myofibroblasts in breast cancer. Recapitulation of tumor environment in culture unravels diversity and implicates converted fibroblasts and recruited smooth muscle cells. J Clin Invest 1995;95(2):859-73. 
85. Direkze NC, Forbes SJ, Brittan M, Hunt T, Jeffery R, Preston SL, et al. Multiple organ engraftment by bone-marrow-derived myofibroblasts and fibroblasts in bone-marrow-transplanted mice. Stem Cells 2003;21(5):514-20.

86. Brittan M, Hunt T, Jeffery R, Poulsom R, Forbes SJ, Hodivala-Dilke K, et al. Bone marrow derivation of pericryptal myofibroblasts in the mouse and human small intestine and colon. Gut 2002;50(6):752-7.

87. Russo J, Russo IH. Atlas and histologic classification of tumors of the rat mammary gland. J Mammary Gland Biol Neoplasia 2000;5(2):187-200.

88. Boland GP, Knox WF, Bundred NJ. Molecular markers and therapeutic targets in ductal carcinoma in situ. Microsc Res Tech 2002;59(1):3-11.

89. Miller F. Xenograft models of premalignant breast disease. J Mammary Gland Biol Neoplasia 2000;5:379-391.

90. Miller FR, Santner SJ, Tait L, Dawson PJ. MCF10DCIS.com xenograft model of human comedo ductal carcinoma in situ [letter]. J Natl Cancer Inst 2000;92(14):1185-6.

91. Tait L, Dawson PJ, Wolman SR, Galea K, Miller FR. Multipotent human breast stem cell line MCF10AT. Int J Oncol 1996;9:263-267.

92. Barsky SH, Doberneck SA, Sternlicht MD, Grossman DA, Love SM. 'Revertant' DCIS in human axillary breast carcinoma metastases. J Pathol 1997;183(2):188-94.

93. Laakso M, Loman N, Borg A, Isola J. Cytokeratin 5/14-positive breast cancer: true basal phenotype confined to BRCA1 tumors. Mod Pathol 2005.

94. Man YG, Tai L, Barner R, Vang R, Saenger JS, Shekitka KM, et al. Cell clusters overlying focally disrupted mammary myoepithelial cell layers and adjacent cells within the same duct display different immunohistochemical and genetic features: implications for tumor progression and invasion. Breast Cancer Res 2003;5(6):R231-41. 


\section{FIGURE LEGENDS}

Figure 1. Location of myoepithelial cells in normal breast ducts and lobules. A. Schematic depiction of a normal duct and lobule. Myoepithelial cells are indicated in black, ductal luminal epithelial cells in pink, while alveolar epithelial cells in beige. Black line denotes the basement membrane. In the ducts myoepithelial cells form a nearly complete layer around the luminal epithelial cells, while in the alveoli the myoepithelial layer is more fenestrated and some luminal epithelial cells are in direct contact with the basement membrane. B. Immunohistochemical analysis of the expression of myoepithelial cell specific genes in normal human breast tissue. Top panel: expression of smooth muscle actin (SMA) is indicated by brown color, while the nuclei are counterstained with hematoxylin. Bottom panel: dual staining for p63 (brown nuclear signal) and pan-cytokeratin (pink cytoplasmic staining) expression. All cells in the basal (myoepithelial) cell layer appear to be positive for SMA, but not for p63.

Figure 2. Hypothetical model depicting breast tumor progression with the different cell types and cell-cell interactions indicated. A. Schematic view of a normal duct, and in situ and invasive carcinomas. In normal breast ducts luminal epithelial cells (pink) lay on top of a layer of myoepithelial cells (black) that are in direct contact with the basement membrane (black line). Stromal cell types include various leukocytes (blue), fibroblasts (pink spindle shape cells), myofibroblasts (black spindle shape cells), adipocytes (yellow round shape cells), and endothelial cells (red rod like cells). Cellular interactions among the different cell types mediated by autocrine and paracrine factors are indicated with arrows. epithelial cells and stromal cells, including fibroblasts (pink spindle-shape cells), adipocytes (round yellow), macrophages (white irregular shape), eosinophil granulocytes (red), lymphocytes (blue circles), and endothelial cells (red rods). In in situ carcinomas, potentially due to the loss of expression of certain chemokines and cytokines and up-regulation of some others, luminal epithelial cells loose their ability to maintain a single epithelial layer. At the same time, the number of myoepithelial cells decreases and the number of stromal fibroblasts, lymphocytes and endothelial cells increases. In invasive 
carcinomas myoepithelial cells and the basement membrane are absent and tumor cells are dispersed in the stroma. B. Immunohistochemical analysis of myoepithelial cell specific gene expression in human normal and cancerous tissue samples. Smooth muscle actin (SMA) is expressed in myoepithelial cells and in myofibroblasts, while p63 is expressed in myoepithelial cells in normal and DCIS tissue, but in a subset of epithelial cells in invasive tumor indicative of basaloid/squamous cell differentiation.

Figure 3. Hypothetical model depicting two views of in situ to invasive carcinoma transition. Cells are depicted as in Figures 1 and 2. In the "escape" model the tumor epithelial cells disrupt the myoepithelial cell layer, degrade the basement membrane, and migrate into the stroma. While in the "release" model the myoepithelial cells disappear and the basement membrane is disrupted at sites coinciding with areas of leukocytic infiltration and accumulation of myofibroblasts. 
Table 1. List of genes specific for normal myoepithelial cells and abnormally expressed in DCIS myoepithelial cells. SAGE tag sequence (Tag), normalized tag numbers in normal epithelial (NE), myoepithelial (NM), and DCIS myoepithelial (DM) cells, their ratios, and the subcellular localization of the encoded protein are listed. Genes were selected based on pair-wise comparison of SAGE libraries generated from normal epithelial and myoepithelial, and DCIS myoepithelial cells, and identifying the statistically significantly $(\mathrm{p}<0.02)$ differentially expressed tags demonstrating at least 10 -fold difference.

\begin{tabular}{|c|c|c|c|c|c|c|c|c|c|}
\hline Tag & NE & NM & DM & Ratio NM/NE & Ratio DM/NM & UniGene & Gene Sym & Description & Location \\
\hline TACTTTATAA & 0 & 287 & 2 & 287 & -170 & Hs.534115 & ADAMTS1 & A disintegrin-like and metalloprotease (reprolysin type) with thrombospondin type 1 motif, 1 & secreted \\
\hline GGGAAGGGAC & 0 & 178 & 3 & 178 & -53 & Hs.269128 & PPP2R1B & Protein phosphatase 2 (formerly $2 \mathrm{~A}$ ), regulatory subunit A (PR 65), beta isoform & \\
\hline ACCTTGGTGC & 0 & 140 & 2 & 140 & -83 & Hs.355214 & KRT14 & Keratin 14 & \\
\hline GTAAATATGG & 2 & 280 & 5 & 120 & -55 & Hs.485616 & DST & Dystonin & secreted \\
\hline TGCTTGTGTA & 0 & 115 & 0 & 115 & -115 & Hs. 121520 & AMIGO2 & Adhesion molecule with Ig-like domain 2 & cell membrane \\
\hline AGGTCTTCAA & 2 & 192 & 22 & 83 & -9 & Hs.164226 & THBS1 & Thrombospondin 1 & secreted \\
\hline TTTTGTATTT & 0 & 80 & 2 & 80 & -48 & Hs.434914 & C14orf31 & FERM domain containing 6 & \\
\hline TCCTGTAAAG & 0 & 73 & 7 & 73 & -11 & Hs.74034 & CAV1 & Caveolin 1, caveolae protein, $22 \mathrm{kDa}$ & cell membrane \\
\hline ATGGTGTATG & 0 & 70 & 2 & 70 & -42 & Hs. 128548 & WDR1 & WD repeat domain 1 & \\
\hline TGTAGGTCAT & 0 & 66 & 5 & 66 & -13 & Hs. 58561 & GPR87 & G protein-coupled receptor 87 & \\
\hline ТTТССТСТСА & 5 & 297 & 15 & 64 & -20 & Hs. 523718 & SFN & Stratifin & cytosol/secreted \\
\hline GATATGTTAT & 0 & 63 & 0 & 63 & -63 & Hs.117938 & COL17A1 & Collagen, type XVII, alpha 1 & secreted \\
\hline CTTCCTTGCC & 44 & 2698 & 118 & 61 & -23 & Hs.2785 & KRT17 & Keratin 17 & \\
\hline TTCTTTTCAT & 0 & 59 & 0 & 59 & -59 & Hs. 522590 & EIF1AX & Eukaryotic translation initiation factor $1 \mathrm{~A}, \mathrm{X}$-linked & \\
\hline AAAGTCATTG & 2 & 133 & 3 & 57 & -39 & Hs.21145 & ODAG & GATA zinc finger domain containing 1 & \\
\hline ACTACTAAGG & 0 & 52 & 0 & 52 & -52 & Hs. 2820 & OXTR & Oxytocin receptor & cell membrane \\
\hline GCTGTAGCCA & 0 & 52 & 0 & 52 & -52 & Hs.483816 & PPARGC1B & Peroxisome proliferative activated receptor, gamma, coactivator 1 , beta & \\
\hline GGAAAGATGT & 0 & 49 & 0 & 49 & -49 & Hs.488293 & EGFR & Epidermal growth factor receptor & cell membrane \\
\hline CTTTCTTTGA & 2 & 77 & 8 & 33 & -9 & Hs.292156 & DKK3 & Dickkopf homolog 3 (Xenopus laevis) & secreted \\
\hline TCATCATCAG & 2 & 77 & 0 & 33 & -77 & Hs.303870 & $\mathrm{KCNC1}$ & Potassium voltage-gated channel, Shaw-related subfamily, member 1 & cell membrane \\
\hline AAGCTGTATA & 2 & 73 & 8 & 32 & -9 & Hs. 143250 & TNC & Tenascin C (hexabrachion) & secreted \\
\hline TGATTGGTGG & 5 & 122 & 3 & 26 & -36 & Hs.74615 & PDGFRA & Platelet-derived growth factor receptor, alpha polypeptide & cell membrane \\
\hline GTTTCATCTC & 5 & 84 & 3 & 18 & -25 & Hs.408767 & CRYAB & Crystallin, alpha B & \\
\hline TCACTGCACT & 9 & 154 & 10 & 17 & -15 & Hs.491322 & PTK2B & PTK2B protein tyrosine kinase 2 beta & \\
\hline TTTGTAGATG & 5 & 70 & 3 & 15 & -21 & Hs. 184233 & HSPA9B & Heat shock $70 \mathrm{kDa}$ protein $9 \mathrm{~B}$ & \\
\hline TATCTGTCTA & 12 & 136 & 2 & 12 & -81 & Hs.436687 & SET & SET translocation & \\
\hline TCTCTACTAA & 9 & 108 & 13 & 12 & -8 & Hs.466088 & TPM4 & Tropomyosin 4 & \\
\hline ACTGAGGAAA & 9 & 105 & 19 & 11 & -6 & Hs.450230 & IGFBP3 & Insulin-like growth factor binding protein 3 & secreted \\
\hline TTCTATTTCA & 7 & 73 & 2 & 11 & -44 & Hs.87752 & MSN & Moesin & \\
\hline TAGCTCTATG & 9 & 98 & 8 & 11 & -12 & Hs.371889 & ATP1A1 & Hypothetical protein MGC16179 & cell membrane \\
\hline GTCCTTTCTG & 12 & 119 & 5 & 10 & -24 & Hs.799 & HBEGF & Heparin-binding EGF-like growth factor & secreted \\
\hline TACCAGTGTA & 9 & 94 & 2 & 10 & -56 & Hs.113684 & HSPD1 & Cadherin 12 , type 2 & cell membrane \\
\hline ACACTTGGAG & 9 & 91 & 3 & 10 & -27 & Hs.221889 & CSDA & Cold shock domain protein $\mathrm{A}$ & \\
\hline GTGATGGTGT & 9 & 84 & 3 & 9 & -25 & Hs.292493 & G22P1 & X-ray repair complementing defective repair in Chinese hamster cells 6 & \\
\hline CTTAAGGATT & 12 & 101 & 5 & 9 & -20 & Hs. 530412 & PAI-RBP1 & PAI-1 mRNA binding protein & \\
\hline TGCTGTGCAT & 19 & 157 & 25 & 8 & -6 & Hs.380774 & DDX3X & DEAD (Asp-Glu-Ala-Asp) box polypeptide 3, X-linked & \\
\hline AGTGTCTGTG & 37 & 304 & 32 & 8 & -10 & Hs. 8867 & CYR61 & Cysteine-rich, angiogenic inducer, 61 & secreted \\
\hline TAAAACAAGA & 12 & 94 & 12 & 8 & -8 & Hs. 527653 & DAF & Decay accelerating factor for complement & secreted \\
\hline TTCATTATAA & 23 & 171 & 5 & 7 & -34 & Hs.459927 & PTMA & Prothymosin, alpha (gene sequence 28) & \\
\hline GTGTAATAAG & 26 & 175 & 17 & 7 & -10 & Hs.487774 & HNRPA2B1 & Heterogeneous nuclear ribonucleoprotein A2/B1 & \\
\hline AGTATGAGGA & 26 & 147 & 30 & 6 & -5 & Hs.211600 & TNFAIP3 & Tumor necrosis factor, alpha-induced protein 3 & \\
\hline TACTAGTCCT & 19 & 105 & 7 & 6 & -16 & Hs. 525600 & HSPCA & Heat shock $90 \mathrm{kDa}$ protein 1 , alpha & \\
\hline TTAAAGATTT & 33 & 175 & 15 & 5 & -12 & Hs. 133892 & TPM1 & Tropomyosin 1 (alpha) & \\
\hline TTCTTGTTTT & 26 & 126 & 13 & 5 & -9 & Hs.472010 & PRNP & Prion protein $(\mathrm{p} 27-30)$ & \\
\hline TACCATCAAT & 107 & 444 & 64 & 4 & -7 & Hs.544577 & GAPD & Glyceraldehyde-3-phosphate dehydrogenase & \\
\hline TTCATACACC & 240 & 793 & 64 & 3 & -12 & Hs. 527213 & DCOHM & 6-pyruvoyl-tetrahydropterin synthase/dimerization cofactor of hepatocyte nuclear factor 1 alpha & \\
\hline TAATAAAGGT & 137 & 409 & 64 & 3 & -6 & Hs. 512675 & RPS8 & Ribosomal protein $\mathrm{S} 8$ & \\
\hline AGAAAGATGT & 184 & 521 & 79 & 3 & -7 & Hs.494173 & ANXA1 & Annexin A1 & cell membrane \\
\hline TTGAAGCTTT & 396 & 1007 & 249 & 3 & -4 & Hs. 75765 & CXCL2 & Chemokine (C-X-C motif) ligand 2 & secreted \\
\hline
\end{tabular}


Table 2. List of genes differentially expressed between normal and DCIS myoepithelial cells, and myofibroblasts. SAGE tag sequence (Tag), normalized tag numbers in normal (NM) and DCIS (DM) myoepithelial cells, and in myofibroblasts (MF), their ratios, and the subcellular localization of the encoded protein are listed. Genes were selected as described above (Table 1).

\begin{tabular}{|c|c|c|c|c|c|c|c|c|c|}
\hline Tag & MF & DM & NM & Ratio DM/NM & Ratio DM/MF & UniGene & Gene Sym & Description & Location \\
\hline AACTTTTGGC & 9 & 81 & 15 & 12 & 9 & Hs. 195471 & PFKFB3 & 6-phosphofructo-2-kinase/fructose-2,6-biphosphatase 3 & \\
\hline TTCATACACC & 377 & 64 & 1648 & -12 & -6 & Hs. 527213 & DCOHM & 6-pyruvoyl-tetrahydropterin synthase/dimerization cofactor of hepatocyte nuclear factor 1 alpha & \\
\hline TAGCTGGAAA & 31 & 395 & 0 & 235 & 13 & Hs.475125 & ATXN10 & Ataxin 10 & \\
\hline GCCTGTCCCT & 203 & 56 & 0 & 33 & -4 & Hs. 821 & BGN & Biglycan & secreted \\
\hline GCGAAACCCA & 11 & 69 & 0 & 41 & 6 & Hs. 17569 & CHST11 & Carbohydrate (chondroitin 4) sulfotransferase 11 & \\
\hline CGGGGTGGCC & 41 & 173 & 0 & 103 & 4 & Hs. 1584 & COMP & Cartilage oligomeric matrix protein & secreted \\
\hline TCCAGGAAAC & 31 & 109 & 0 & 65 & 4 & Hs. 11590 & CTSF & Cathepsin $\mathrm{F}$ & cytosolic/secreted \\
\hline GCTGAACGCG & 71 & 336 & 65 & 11 & 5 & Hs. 517106 & СEBPB & CCAAT/enhancer binding protein (C/EBP), beta & \\
\hline AGGCTCCTGG & 18 & 200 & 15 & 29 & 11 & Hs. 483444 & CXCL14 & Chemokine (C-X-C motif) ligand 14 & secreted \\
\hline GAATTCACAA & 20 & 113 & 0 & 67 & 6 & Hs. 482562 & F2R & Coagulation factor II (thrombin) receptor & cell membrane \\
\hline GGGCCAACCC & 14 & 87 & 0 & 52 & 6 & Hs.501309 & CIRBP & Cold inducible RNA binding protein & \\
\hline CTGTCAGCGT & 213 & 69 & 0 & 41 & -3 & Hs.405614 & CTHRC1 & Collagen triple helix repeat containing 1 & secreted \\
\hline TTTGGTTTTC & 760 & 252 & 0 & 150 & -3 & Hs.489142 & COL1A2 & Collagen, type I, alpha 2 & secreted \\
\hline GGTGAGCCGG & 10 & 69 & 0 & 41 & 7 & Hs.420269 & COL6A2 & Collagen, type VI, alpha 2 & secreted \\
\hline CAGATAAGTT & 23 & 207 & 0 & 123 & 9 & Hs. 409662 & COL14A1 & Collagen, type XIV, alpha 1 & secreted \\
\hline TTGGGATGGG & 13 & 116 & 0 & 69 & 9 & Hs. 154224 & CFHL1 & Complement factor $\mathrm{H}$-related 1 pseudogene & secreted \\
\hline ACCGGCGCCC & 2 & 77 & 0 & 46 & 39 & Hs.476092 & TNA & C-type lectin domain family 3 , member B & secreted \\
\hline AGTGTCTGTG & 120 & 32 & 632 & -10 & -4 & Hs.8867 & CYR61 & Cysteine-rich, angiogenic inducer, 61 & secreted \\
\hline GCGTCGGTGC & 9 & 89 & 0 & 53 & 10 & Hs. 155597 & DF & D component of complement (adipsin) & secreted \\
\hline GAGGAGGAGA & 8 & 64 & 0 & 38 & 8 & Hs. 127092 & DHX38 & DEAH (Asp-Glu-Ala-His) box polypeptide 38 & \\
\hline ACTTATTATG & 448 & 121 & 7 & 35 & -4 & Hs. 156316 & DCN & Decorin & secreted \\
\hline GGCAGGCGGG & 27 & 138 & 29 & 10 & 5 & Hs.440332 & ERF & Ets2 repressor factor & \\
\hline GGGTAGGGGG & 80 & 458 & 15 & 65 & 6 & Hs. 75678 & FOSB & FBJ murine osteosarcoma viral oncogene homolog B & \\
\hline CCGTGACTCT & 55 & 187 & 58 & 7 & 3 & Hs. 269512 & FSTL1 & Follistatin-like 1 & secreted \\
\hline TCACCGGTCA & 72 & 352 & 7 & 101 & 5 & Hs.522373 & GSN & Gelsolin & secreted \\
\hline TAGCTGGAAC & 5 & 59 & 0 & 35 & 12 & Hs. 508364 & GPC5 & Glypican 5 & cell membrane \\
\hline AACTCCCAGT & 73 & 839 & 15 & 120 & 12 & Hs. 110571 & GADD45B & Growth arrest and DNA-damage-inducible, beta & \\
\hline TACTAGTCCT & 90 & 7 & 218 & -16 & -13 & Hs. 525600 & HSPCA & Heat shock $90 \mathrm{kDa}$ protein 1 , alpha & \\
\hline TGTAATCAAT & 59 & 7 & 152 & -11 & -9 & H. 546261 & HNRPA1 & Heterogeneous nuclear ribonucleoprotein $\mathrm{A} 1$ & \\
\hline GGGCAGGCGT & 89 & 320 & 44 & 15 & 4 & Hs.501629 & IER2 & Immediate early response 2 & \\
\hline CTAACGGGGC & 11 & 150 & 0 & 89 & 14 & Hs. 513022 & ISLR & Immunoglobulin superfamily containing leucine-rich repeat & \\
\hline GGGGGGGGGT & 10 & 136 & 0 & 81 & 14 & Hs. 523414 & IGF2 & Insulin-like growth factor 2 & secreted \\
\hline GGCCCCTCAC & 8 & 86 & 0 & 51 & 11 & Hs. 274313 & IGFBP6 & Insulin-like growth factor binding protein 6 & secreted \\
\hline CATATCATTA & 499 & 160 & 0 & 95 & -3 & Hs. 479808 & IGFBP7 & Insulin-like growth factor binding protein 7 & secreted \\
\hline GGAAAAATTC & 21 & 82 & 7 & 24 & 4 & Hs. 429052 & ITGB1 & Integrin, beta 1 & cell membrane \\
\hline GGCACCTCAG & 16 & 124 & 7 & 36 & 8 & Hs. 512234 & IL6 & Interleukin 6 & secreted \\
\hline ACCCCCCCGC & 119 & 1112 & 22 & 106 & 9 & Hs. 2780 & JUND & Jun D proto-oncogene & \\
\hline GGAGGGGGCT & 37 & 128 & 44 & 6 & 3 & Hs.491359 & LMNA & Lamin A/C & \\
\hline TTATGTTTAA & 655 & 77 & 7 & 22 & -8 & Hs.406475 & LUM & Lumican & secreted \\
\hline AGAACCTTCC & 49 & 190 & 44 & 9 & 4 & Hs. 181244 & HLA-A & Major histocompatibility complex, class I, A & cell membrane \\
\hline GGAAATGTCA & 227 & 562 & 87 & 13 & 2 & Hs.513617 & MMP2 & Matrix metalloproteinase 2 & secreted \\
\hline AGGGAGCAGA & 28 & 172 & 0 & 102 & 6 & Hs. 296049 & MFAP4 & Microfibrillar-associated protein 4 & secreted \\
\hline GACGGCTGCA & 21 & 93 & 7 & 26 & 4 & Hs. 380906 & MYADM & Myeloid-associated differentiation marker & \\
\hline GGTGCCCAGT & 14 & 84 & 7 & 24 & 6 & Hs. 519909 & MARCKS & Myristoylated alanine-rich protein kinase $\mathrm{C}$ substrate & \\
\hline GAAAAATTTA & 33 & 136 & 22 & 13 & 4 & Hs. 448588 & NGFRAP1 & Nerve growth factor receptor (TNFRSF16) associated protein 1 & \\
\hline TAGTTGGAAA & 23 & 338 & 44 & 16 & 15 & Hs. 524430 & NR4A1 & Nuclear receptor subfamily 4, group A, member 1 & \\
\hline TGCGCTCTCC & 22 & 91 & 0 & 54 & 4 & Hs.25391 & PI16 & Protease inhibitor 16 & secreted \\
\hline GAGATCCGCA & 15 & 76 & 0 & 45 & 5 & Hs. 75348 & PSME1 & Proteasome activator subunit 1 & \\
\hline TTCATTATAA & 157 & 5 & 356 & -34 & -31 & Hs. 459927 & PTMA & Prothymosin, alpha & \\
\hline CACACAGTTT & 51 & 192 & 29 & 14 & 4 & Hs. 502876 & RHOB & Ras homolog gene family, member B & \\
\hline GACACGAACA & 19 & 89 & 7 & 26 & 5 & Hs. 25829 & RASD1 & RAS, dexamethasone-induced 1 & \\
\hline ATTTCTTCAA & 307 & 81 & 0 & 48 & -4 & Hs.481022 & SFRP2 & Secreted frizzled-related protein 2 & secreted \\
\hline TCAACTTCTG & 20 & 133 & 0 & 79 & 7 & Hs. 419240 & SLC2A3 & Solute carrier family 2 , member 3 & cell membrane \\
\hline AGCCCTACAA & 128 & 498 & 312 & 3 & 4 & Hs.469331 & STARD7 & START domain containing 7 & \\
\hline GCTTGCAAAA & 30 & 219 & 109 & 4 & 7 & Hs. 487046 & SOD2 & Superoxide dismutase 2 , mitochondrial & \\
\hline ССТСCCAGCT & 28 & 141 & 7 & 40 & 5 & Hs.527973 & SOCS3 & Suppressor of cytokine signaling 3 & \\
\hline GTCAAAATTT & 48 & 150 & 0 & 89 & 3 & Hs. 371147 & THBS2 & Thrombospondin 2 & secreted \\
\hline GGGGAAATCG & 272 & 681 & 160 & 9 & 3 & Hs.446574 & TMSB10 & Thymosin, beta 10 & \\
\hline TACATAATTA & 39 & 3 & 218 & -31 & -12 & Hs. 523789 & TncRNA & Trophoblast-derived noncoding RNA & \\
\hline TСТСТАСТАA & 79 & 13 & 225 & -8 & -6 & Hs. 466088 & TPM4 & Tropomyosin 4 & \\
\hline TGGAAAGTGA & 351 & 1176 & 65 & 37 & 3 & Hs. 25647 & FOS & V-fos FBJ murine osteosarcoma viral oncogene homolog & \\
\hline ATGGTGGGGG & 143 & 427 & 240 & 4 & 3 & Hs. 534052 & ZFP36 & Zinc finger protein $36, \mathrm{C} 3 \mathrm{H}$ type, homolog & \\
\hline CTGCCAAGTT & 51 & 187 & 65 & 6 & 4 & Hs. 490415 & ZYX & Zyxin & cell membrane \\
\hline
\end{tabular}


A
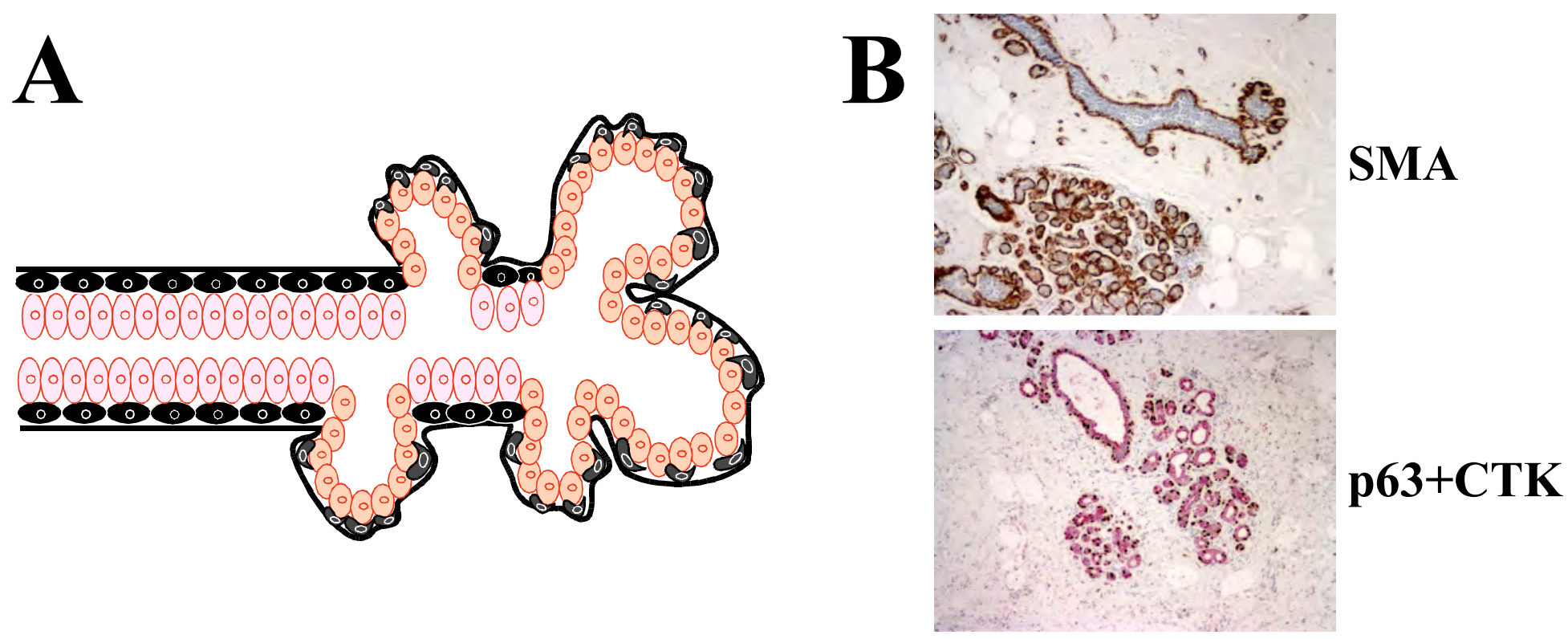


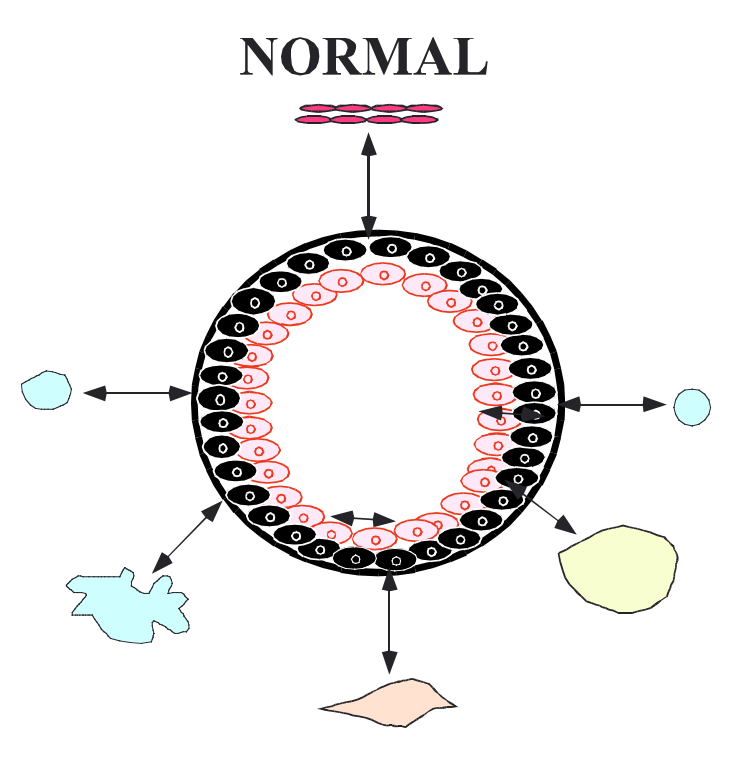

IN SITU CARCINOMA
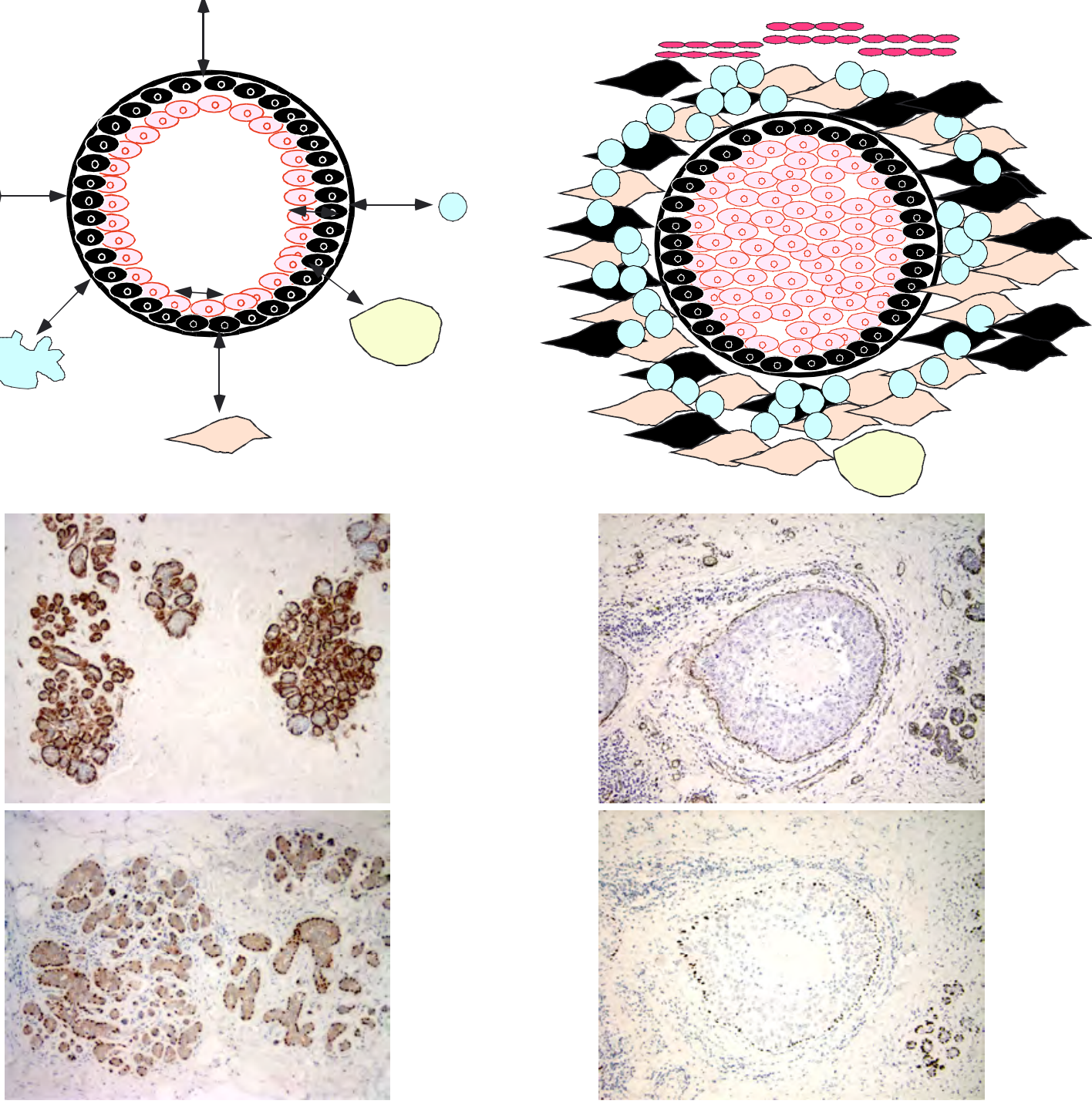

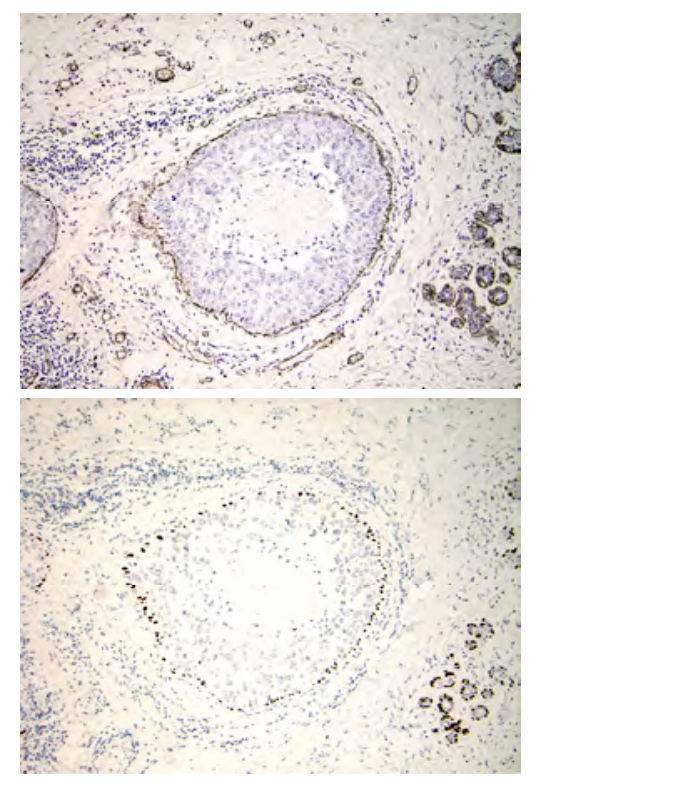

INVASIVE CARCINOMA
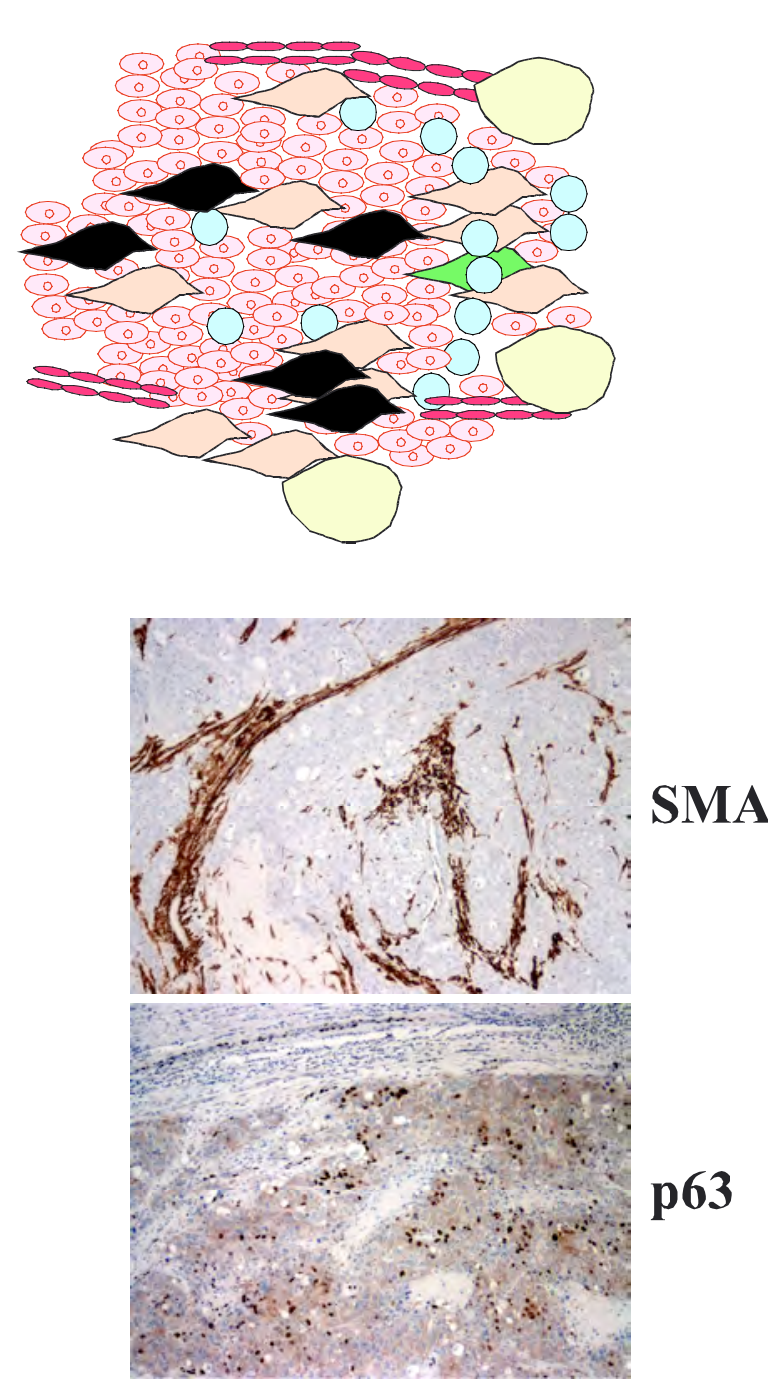
INVASIVE CARCINOMA

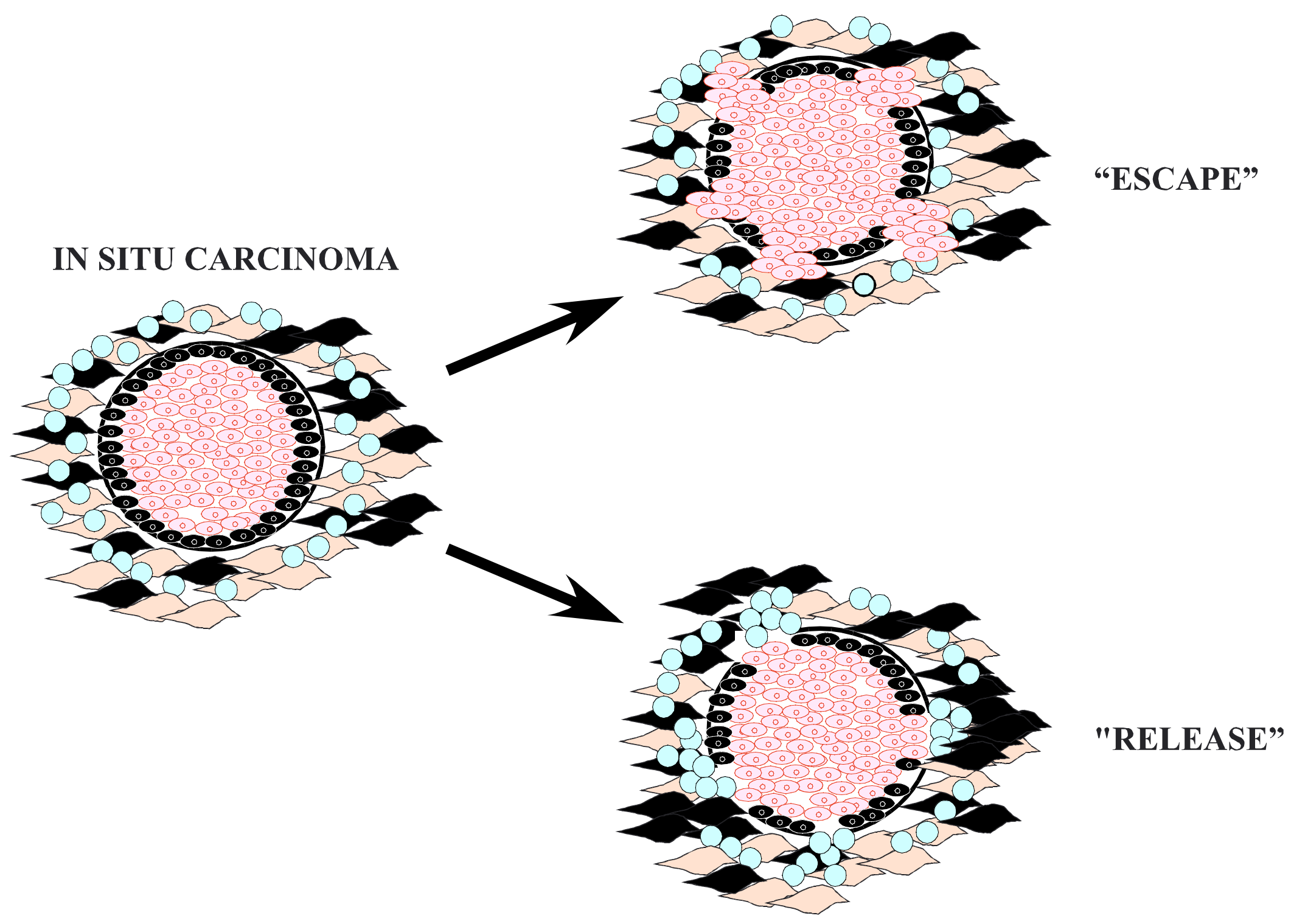

